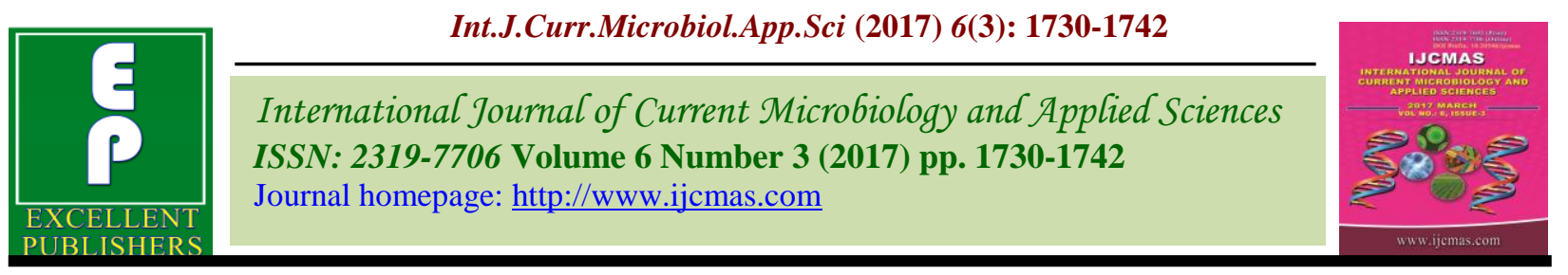

Review Article

https://doi.org/10.20546/ijcmas.2017.603.199

\title{
Micro Climate Control in Greenhouse
}

\author{
D.T. Santosh*, K.N. Tiwari, Vikas Kumar Singh and A. Raja Gopala Reddy \\ Precision Farming Development Centre, Agricultural and Food Engineering Department, \\ IIT Kharagpur, India \\ *Corresponding author
}

\begin{tabular}{|c|c|}
\hline & A B S T R A C T \\
\hline $\begin{array}{l}\text { Greenhouse, } \\
\text { Microclimate, } \\
\text { Climate control, } \\
\text { Greenhouse heating. }\end{array}$ & \multirow{3}{*}{$\begin{array}{l}\text { Microclimate of green houses is important for better plant growth and greater yield. The } \\
\text { dynamic behavior of the greenhouse microclimate is a combination of physical processes } \\
\text { involving energy transfer and mass balance. The greenhouse microclimate can be } \\
\text { manipulated by control actions, such as heating, ventilation, carbon dioxide enrichment to } \\
\text { provide appropriate environmental conditions for crops. These modifications imply the } \\
\text { additional use of energy in the production process. Because of its complexity, excessive } \\
\text { climatic conditions in greenhouses can adversely affect the growing environment for } \\
\text { crops. An optimal ambient control is needed to accomplish complicated processes } \\
\text { involved in greenhouse energy balancing, including low emissions and reduced production } \\
\text { costs. In this paper the information available on microclimate parameters involved in } \\
\text { greenhouse, methods to control them and their impact on the crops grown in the structure } \\
\text { are presented. }\end{array}$} \\
\hline Article Info & \\
\hline $\begin{array}{l}\text { Accepted: } \\
\text { 24 February } 2017 \\
\text { Available Online: } \\
10 \text { March } 2017\end{array}$ & \\
\hline
\end{tabular}

\section{Introduction}

During last two decades in India, the productivity and efficiency of horticultural production have received particular attention and key concept has been to accelerate plant growth to achieve maximum production. Protected cultivation makes it possible to obtain increased crop productivity maintaining a favourable environment for the plants. Therefore, production in greenhouses has become more popular than in the past. A greenhouse can be defined as a "framed or an inflated structure with a transparent or translucent material in which crops could be grown under the condition of at least partially controlled environment and which is large enough to permit persons to work within it to carry out cultural operations" (Tiwari, 2003).
The design and selection of acontrolled environment greenhouse depends upon the climatic conditions of each zone and plants requirement. India has six climatic zones on the basis of rainfall, relative humidity, ambient air temperature and insolation. These zones are: hot and dry considering Centre as Jodhpur, warm and humid for Chennai, moderate for Bangalore, cold and cloudy at Srinagar and composite at New Delhi (Bansal and Minke, 1988).

The inside environment (microclimate) of a greenhouse is influenced by factors such as light, temperature, humidity and carbon dioxide concentration. The effects of greenhouse environment on growth, 
development and productivity of crops have been studied by many researchers. Crop yield mainly depends on the responses of plants to environmental influences (Ellis et al., 1990) for example, temperature has considerable influence on crop timing and yield (Pearson et $a l ., 1995)$ and light is primary determinant of crop growth. Greenhouse air temperature, humidity and plant leaf temperature are in turn affected by the light transmission of the cover material.

Micro climate control in greenhouses is one of the first priority problems since even despite good genetic properties of crops, the quality of fertilizers and soil, incorrect maintenance of temperature, humidity mode of the greenhouse and poor dosing by the carbon dioxide may result in a considerable drop in productivity up to the loss of crops. The process of variation of the microclimate of the greenhouse is complex, multi parametric and depends on a set of external and internal factors. The external factors are: ambient temperature, humidity, intensity of solar radiation, the direction and velocity of wind, etc. The geometric dimensions of the greenhouse, the location of elements of heating and ventilation systems, types of soil, genetic properties and kinds of crops etc. are the internal factors.

Micro climate of greenhouse can be scientifically controlled to an optimum level throughout the cultivation period to increase the productivity by several folds. Greenhouse also permits to cultivate four to five crops in a year with controlled microclimate, efficient use of various inputs like water, fertilizer and seeds and plant protection chemicals. In addition, automation of irrigation, precise application of other inputs and environmental controls by using computers and artificial intelligence is possible for the acclimatization of tissue culture plants and high value crops in greenhouses.

\section{Greenhouse micro climate parameters}

Plants require specific climatic factors to enhance growth resulting from photosynthesis. Some of the important microclimate parameters such as solar radiation, temperature, relative humidity, light and carbon dioxide are detailed in the sections below.

\section{Solar radiation}

The production of plant dry matter decreases almost linearly with the decrease in solar radiation values. The growth comes to a halt at the compensation point, which is at 14-30 $\mathrm{W} / \mathrm{m}^{2}$ light power for plants $(0.1$ $\mathrm{kWh} / \mathrm{m}^{2}$ day).An efficient production of dry matter cannot be expected in higher latitudes during winter without artificial lighting. The minimum amount of irradiation necessary to ensure sufficient growth and flowering corresponds to a daily global radiation of 2.0$2.3 \mathrm{kWh} / \mathrm{m}^{2}$ day (Nisen et al., 1984). Most important for photosynthesis, i.e., the growth of plants is solar radiation power $\left(\mathrm{W} / \mathrm{m}^{2}\right)$.

\section{Temperature}

Temperature has a direct impact on the physiological development phases (flowering, germination, development) of the plant, regulates the transpiration rate and plant water status through stomatal control during the photosynthesis. Temperature requirements in a green house depend largely on the type of crop to be grown. Each crop and its development process responds differently to temperature. The difference between day and night temperatures, as well as the average 24hour temperatures can also affect plant growth. Low temperatures can have a significant effect on growth rates and can influence fruit and seed production. Temperature of climate area plays a large role in designing structures and control systems. 
Temperature is the most important variable of the greenhouse climate that can and needs to be controlled. The majorities of plants grown in greenhouses are warm season species and are adapted to average temperatures in the range $20-30^{\circ} \mathrm{C}$, with approximate lower and upper temperature limits of $10^{\circ} \mathrm{C}$ and $35^{\circ} \mathrm{C}$. If the average minimum outside temperature is below $10^{\circ} \mathrm{C}$ the greenhouse requires heating, particularly at night. When the average maximum outside temperature is less than $27^{\circ} \mathrm{C}$ ventilation will prevent excessive internal temperatures during the day; however, if the average maximum temperature exceeds $27-28^{\circ} \mathrm{C}$ then artificial cooling is necessary. The maximum greenhouse temperature exceeding $35{ }^{0} \mathrm{C}$ for prolonged periods is harmful for majority crops.

\section{Relative humidity}

Vapour pressure deficit (VPD) is the difference between the air's moisture content and the amount of moisture air can hold when it is saturated. High VPD usually caused by high temperatures and low humidity and affects plant growth by causing high stomatal resistance and plant water stress and the plant transpires more water than it can absorb. Low VPD, in turn, caused low plant transpiration and associated physical disorders. Maintaining the VPD above some minimum value helps to ensure adequate transpiration and also reduces disease problems. Relative humidity within the range $60-90 \%$ is suitable to plant growth. Values below $60 \%$ may occur during ventilation in arid climates, or when plants are young with small leaves, and this can cause water stress. Serious problems can occur if the relative humidity exceeds 95 $\%$ for long periods, particularly at night as this favours the rapid development of fungus diseases. During the day, humidity can usually be reduced using ventilation. However, at night, unless the greenhouse is heated, the internal and external temperatures may be similar and if the external humidity is high reducing the greenhouse humidity is not easy.

\section{Light intensity}

The growth of plants is controlled by three light (photo) processes, namely photosynthesis, photo morphogenesis and photoperiodism. Every variation in light has a direct effect on these processes. Light is part of the photosynthesis process, by converting carbon dioxide into organic material and then releasing oxygen in the presence of light. Photo morphogenesis is the way of plants developing under the influence of different types of light and photo periodism is how the plant reacts to different day lengths and whether it will seed or flower. The most important process is photosynthesis and light is the primary energy source to enable this process. In many parts of India, light levels are generally sufficient for effective plant production and artificial lighting is only needed for those crops that need longer day lengths. For horticultural purposes, we are usually interested in measuring three properties of light which are irradiance, spectral quality and duration. Combinations of these three characteristics determine the amount of instantaneous and cumulative energy that is available for photosynthesis.

\section{Carbon dioxide}

The Carbon dioxide $\left(\mathrm{CO}_{2}\right)$ concentration inside a greenhouse can drop significantly below outside level when a dense crop is growing, even if the greenhouse is well ventilated. The concentration can drop to less than $200 \mu \mathrm{mol} \mathrm{mol}^{-1}$ during winter in mild climate regions. As the $\mathrm{CO}_{2}$ concentration limits the photosynthesis of most vegetable species, the productivity decreases. The optimal $\mathrm{CO}_{2}$ concentration for growth and yield seems to be $700-900 \mu \mathrm{mol} \mathrm{mol}^{-1}$ (De Pascale and Maggio, 2008). The 
$\mathrm{CO}_{2}$ concentrationshould be kept to at least the outside level, but $\mathrm{CO}_{2}$ enrichment is not a current practice in mild climates up to now. $\mathrm{CO}_{2}$ enrichment is essential to increase quality of produce indeed, continuous or periodical increase of $\mathrm{CO}_{2}$ inside the greenhouse may lead to an increase of over 20 percent in fruit production for both dry and fresh matter (Shanchez-Guerrero et al., 2005). Better control of the greenhouse aerial environment can improve marketable yield and quality, and extend the growing season (Bailley, 2000). $\mathrm{CO}_{2}$ is absorbed via stomata in the plant and effective absorption of $\mathrm{CO}_{2}$ in a greenhouse is, therefore, strongly dependent on other climate factors affecting the stomata openings in the plant.

\section{Micro climate control}

All greenhouse cultivation systems regardless of geographic location consist of fundamental climate control components, and depending on their design and complexity, they can provide a greater or lesser amount of climate control, and subsequent plant growth and productivity. Moreover, we need an optimal ambient control to accomplish these complicated objectives, including low emissions and reduced production costs. Micro climate control system includes climatic parameters of inside greenhouse (soil and air temperature, relative humidity, $\mathrm{CO}_{2}$ concentrations, electrical conductivity and soil moisture), outside greenhouse (temperature, relative humidity, solar radiation, wind speed, wind direction and rainfall rate) and equipment (pipe temperature, vents and curtains position). Each microclimate parameter should be maintained at optimal level, which is determined by a type and state of the crop.

\section{Ventilation cooling and shading}

Minimizing the heat load is the major concern for greenhouse climate management in hot climate conditions. This can be achieved by using reducing incoming solar radiation, removing the extra heat through air exchange and increasing the fraction of energy partitioned into latent heat. Shade nets and whitewash (lime or paint application on cladding material) are the major existing methods used to reduce the income of solar radiation. Greenhouse ventilation is an effective way to remove the extra heat through air exchange between inside and outside, when outside air temperature is lower. Evaporative cooling is the common technique to reduce sensible heat load by increasing the latent heat fraction of dissipated energy. Other cooling technical solutions are available (heat pump, heat exchangers), but are not yet widely used, especially in India, because investment cost is yet very high.

\section{Natural ventilation}

Ventilation affects the temperature inside the greenhouse during times of high solar radiation, it is necessary to circulate air from the outside to the inside of the greenhouse in a homogeneous manner in order to remove excess heat. Poor ventilation has a negative impact on indoor air composition, mainly by reducing the $\mathrm{CO}_{2}$ concentration (Lorenzo et al., 1990). Inadequate ventilation generates overheating and excessive transpiration, leading to problems such as plant water stress and physiological disorders, including fruit cracking and abortion of flowers and fruits. On the other hand, natural ventilation helps to evacuate excess moisture and prevent its accumulation in the air layer near the leaves which can cause condensation, leading to the onset of diseases.

Natural ventilation is the result of pressure differences created by wind and temperature gradients between the inside and outside of a greenhouse. It occurs through openings in the greenhouse structure. It controls humidity and 
temperature build up within the greenhouse and can ensure sufficient air exchange. Natural ventilation is a process that directly influences the climate inside the greenhouse (Kittas et al., 1996) and is a decisive factor when it comes to designing. A properly designed ventilation system can improve climate control and consequently, optimize energy use. In addition, ventilation is related to other factors such as temperature, humidity and $\mathrm{CO}_{2}$ concentration, which directly influences the growth and development of crops (Kittas et al., 1996). The efficiency of natural ventilation depends on factors such as wind speed and direction, temperature differences between the outside and the inside of the greenhouse, greenhouse design and the presence or absence of crops (Ould-Khaoua et al., 2006).

Good ventilation in the greenhouse can be achieved with a combination of a roof vent, front doors and fans. One of the simplest and more effective ways to reduce the difference between inside and outside air temperature is to improve ventilation. If the greenhouse is equipped with ventilation openings, both near the ground and at the roof, then this type of ventilation replaces the internal hot air by external cooler one during the hot sunny days with weak wind. The external cool air enters the greenhouse through the lower side openings while the hot internal air exits through the roof openings due to density difference between air masses of different temperature causing the lowering of temperature in the greenhouse. Sufficient ventilation is very important for optimal plant growth, especially in case of high outside temperature and solar radiation. In order to study the variables determining the greenhouse air temperature and to decide about the necessary measures for greenhouse air temperature control a simplified version of the greenhouse energy balance is formulated. According to Kittas et al., (2005), the greenhouse energy balance can be simplified to:

$$
V_{a}=\frac{0.0003 \pi R_{g, 0}-\max }{\Delta T}
$$

where,

$V_{a} \quad=$ ratio of $\mathrm{Q} / \mathrm{Ag}$,

$\mathrm{Q} \quad=$ ventilation flow rate, $\mathrm{m}^{3}$ [air] $\mathrm{s}^{-1}$

$\mathrm{Ag}=$ greenhouse ground surface area, $\mathrm{m}^{2}$

$\tau=$ greenhouse transmission coefficient to solar radiation

$R s, o-\max =$ maximum outside solar radiation, $\mathrm{W} \mathrm{m}{ }^{-2}$

$\Delta T=$ temperature difference between greenhouse and outside air, ${ }^{0} \mathrm{C}$.

The necessary ventilation rate can be obtained by natural or by forced ventilation. For effective ventilation, ventilators should, if possible, be located at the ridge, on the side walls and the gable. Total ventilator area equivalent to $15-30 \%$ of floor area was recommended by White and Aldrich (1975). Above $30 \%$, the effect of additional ventilation area on the temperature difference was very small.

Researchers also studied the effect of insect proof nets in roof openings on greenhouse microclimate. However, the obstruction offered by nets to flow through the openings results in air velocity reduction and higher temperature and humidity as well as an increase of the thermal gradients within the greenhouse (Katsoulas et al., 2006).

\section{Forced ventilation}

The principle of forced ventilation is to create an air flow through the house. Fans suck air out on the one side and openings on the other side let air in. Forced ventilation by fans is the most effective way to ventilate a greenhouse, but consumes electricity. Fans are installed to maintain uniform temperature and humidity inside the greenhouse. The fresh air enters at one side and replaces hot stale air that moves 
out at the opposite side of the greenhouse. Ventilation fans should be located on the wind side of the greenhouse and the distance between two fans should not exceed 8-10 m. Furthermore, an inlet opening on the opposite side of a fan should be at least 1.25 times of the fan area. The velocity of the incoming air must not be too high. The air speed should not exceed $0.5 \mathrm{~m} \mathrm{~s}^{-1}$ in the greenhouse with crop. The openings must be closed automatically when the fans are not in operation.

\section{Shade covers}

The reduction of air temperature is one of the main tasks for greenhouses constructed in India due to occurrence of high temperatures in almost eight months. Direct solar radiation is the primary source of heat gain in greenhouses. This can be controlled by shading or reflection. Shading will be done using different approaches: provision of internal or external shade screens, paints and nets. Shading might negatively influence plant development and photosynthesis because of the reduction of light and the possible effect on ventilation rates/gas exchanging. Hence, care has to be taken when deciding on the type of shading and associated control strategies.

Shade nets when correctly chosen and installed, can contribute to optimize crop production in periods or places where temperature and solar radiation are adverse. According to Briassoulis et al., (2007), shade nets not only contribute to the production increase but also have a positive effect on the quality and homogeneity of the production. Nets are more effective in hot and sunny regions (Al-Helal and Abdel-Ghany, 2010). The use of different combinations of shading materials in greenhouses has got interest among crop growers, especially those who cultivate ornamental plants and looking for the ideal conditions for production. Now in market extensive variety of plastic nets with different optical characteristics are available. The producers can use different shade nets with special optical properties which modify the composition of the transmitted solar radiation to the interior of the greenhouse in improving the performance of the crops (Oren-Shamir et al., 2001). According to Robledo and Martin (1981) the color and transparency of the covering materials affect absorption, reflection and transmission for short and long wave radiations.

The colored shade nets in the protected crops stimulate specific morphological and physiological reactions thereby improves the qualitative of produce (Shahak et al., 2002). Nomura et al., (2009) suggested colored nets as an alternative to substitute the vegetal regulators, since they have the capacity to modify the spectrum of the solar radiation, beyond promoting a physical protection of the plants.

Shade nets mounted inside greenhouse decreases wind speed, thus lessening the leaf boundary layer and reducing the availability of air $-\mathrm{CO}_{2}$ concentration near the leaf surface. The response of plants to light intensity and quality is relevant in greenhouse production where shade nets are used for reducing the radiation load inside the greenhouse. A strong reduction of solar radiation is expected to slow down the leaf transpiration rate thereby increasing the canopy temperature (Jakson et al., 1981).

\section{Evaporative cooling}

One of the most efficient solutions for alleviating the climatic conditions is to use evaporative cooling systems, based on the conversion of sensible heat into latent heat by means of evaporation of water supplied directly into the greenhouse atmosphere (mist or fog system, sprinklers) or through 
evaporative pads (wet pads). Fogging system is based on spraying the water as small droplets with high pressure into the air above the plants in order to increase the water surface in contact with the air. Freefall velocity of these droplets is slow and the air streams inside the greenhouse easily carry the drops. This can result in high efficiency of water evaporation combined with keeping the foliage dry. Fogging is also used to create high relative humidity along with cooling inside the greenhouse. A wide range for fogging system are available their cooling efficiency are reported in the literature.

The fan pad cooling system is most commonly used in horticulture. The fan pad system consists of a fan on one gable end and a wet pad on the opposite end. A small stream of water runs over the pad continuously and air is drawn through the pad by the fans, absorbing heat and water vapour in the greenhouse. It is essential that the pad be free of leaks through which air could pass without making contact with the pad. Different pad materials are available, such as wood, wool, swelling clay minerals, and specially impregnated cellulose paper. These installations have shown a reduction in air temperature of up to $12^{\circ} \mathrm{C}$, even under very high ambient temperatures. It also increases the humidity of the internal air. Air from outside is blown through pads with as large a surface as possible. Uniform shading of greenhouse with nets results in desired cooling during summer. The water flow rate, water distribution system, pump capacity, recirculation rate and output rate of the fan pad cooling system must be carefully calculated and designed to provide a sufficient wetting of the pad to avoid deposition of dissolved material on it. The advantage of fogging systems over wet pad systems is the uniformity of conditions throughout the greenhouse, therefore eliminating the need for forced ventilation and airtight enclosure. Whereas disadvantages are that it is an expensive installation with high operation costs, namely, freshwater supply, electricity and the maintenance costs.

Roof evaporative cooling includes spraying water onto the external surface of a roof and this creates a thin water layer on the surface. This decreases the solar radiation transmissivity to the greenhouse and increases the evaporation rate which consequently decreases the water temperature and closely surrounding air. This system works most effectively in hot and dry climate regions.

\section{Greenhouse heating}

Greenhouse heating is required in cold climate regions such as Himalayan region of the country. Heating costs have a critical influence on the profitability of greenhouse production. Apart from the costs, energy consumption and associated environmental problems through the emission of noxious gases are the constraints in greenhouse operation.

ASAE (2000) proposed greenhouse heating $(\mathrm{Hg})$ requirement which can be estimated by

$H_{g}=U A\left(T_{i}-T_{0}\right)$

where,

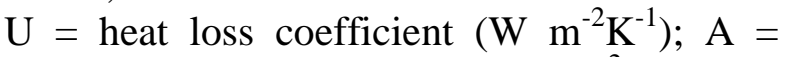
exposed greenhouse surface area $\left(\mathrm{m}^{2}\right)$

$\mathrm{T}_{\mathrm{i}}=$ inside air temperature, $(\mathrm{K}) ; \quad \mathrm{T}_{0}=$ outside air temperature $(\mathrm{K})$

The heating system should provide heat to the greenhouse at the same rate at which it is lost. There are several popular heating systems for greenhouses. The most common and least expensive is the unit heater system.

\section{Unit heaters}

In this system the warm air is blown from unit heaters that have self-contained fireboxes. 
Heaters are located throughout the greenhouse, each heating system has a floor area of 180 to $500 \mathrm{~m}^{2}$.

\section{Central heating}

Heat is half dissipated through radiation and half through convective transfers. Unlike unit heater system a portion from the heat from central boiler systems is delivered to the root and crown zone of the crop. This can lead to improved growth of the crop and to a higher level of disease control.

\section{Wall pipes coils}

Perimeter wall heating can partially provide the additional heat required and contribute to a uniform thermal environment in the greenhouse. Both bare and finned pipe applications are commonly used.

\section{Overhead pipes coils}

Heat loss through the roofs and gables is supplied through an overhead coil of pipes that is situated across the entire greenhouse. The overhead coil is not the most desirable source of heat because it is located above the plants.

\section{In bed-pipe coils}

By placing the heating pipes near the base of the plants, the roots and crown of the plants are heated better than in the overhead system. Air movement caused by the warmer under bench pipe reduces the humidity around the plant.

\section{Pipe/Rail heating systems}

This type of heating system maintains uniform temperatures and positively affects the microclimate of plants. Air movement caused by the warmer pipe/rail reduces the humidity around the plant. Such systems are suitable for vegetable production systems.

\section{Heating for anti frost protection}

In these greenhouses heating was used to protect crops from freezing. It is also used to keep air temperature in greenhouse in levels above critical thresholds for condensation control. These greenhouses are not equipped with heavy and complicated heating systems.

\section{Solar radiation filtration}

Global solar radiation entering in a greenhouse composed of three types of radiation, namely ultraviolet radiation (UV), photosynthetic active radiation (PAR) and near infrared radiation (NIR). Most of the UV radiation is absorbed by the Earth's atmosphere. The extreme exposure of plants to UV can result in the degradation of the photosynthetic process. PAR is absorbed by the plant and is important for photosynthesis and plant growth. NIR is less absorbed by the plant and more by the greenhouse structure and equipment, causing the increase in ambient temperature in the greenhouse. Cooling of greenhouse is done by modifying the cover materials. NIR filtering is also done by using specific plastic cellophanes, moveable screens or NIR filtering shading paint.

\section{Internal air circulation system}

Internal air velocities of a greenhouse are recommended to be between 0.5 to $0.7 \mathrm{~m} \mathrm{~s}^{-1}$ for optimal plant growth, by facilitating gas exchange ( $\mathrm{CO}_{2}$ and water vapour). To ensure this, fans are often installed above the crop. The number of fans to be installed in the greenhouse is calculated to ensure air circulation of $0.01 \mathrm{~m}^{3} \mathrm{~s}^{-1}$ per $\mathrm{m}^{2}$ and should be installed in the direction of the ridge. Normally distances between the fans should not exceed 30 times the diameter of the fans. 


\section{$\mathrm{CO}_{2}$ enrichment}

Many literatures described positive effect of $\mathrm{CO}_{2}$ enrichment systems on plant growth. $\mathrm{CO}_{2}$ is added to the room to improve the process of photosynthesis. Pure liquid $\mathrm{CO}_{2}$ pumping from containers to the greenhouse is the purest type of $\mathrm{CO}_{2}$ enrichment. A better $\mathrm{CO}_{2}$ distribution within the greenhouse can be accomplished with a pipeline network, similar to the fertigation system. Special gauges are installed on the distribution pipes for $\mathrm{CO}_{2}$ concentration measurement, in order to detect possible gases hazard. Like many other systems, it does not have the greenhouse heating effect. The disadvantage of this system is the high cost of transporting gas containers. Fuel combustion or burning liquid kerosene, propane-butane gas or natural gas produces $\mathrm{CO}_{2}$ as part of the gas emissions through the burners. Heat is also produced by this type of operation and is often the primary reason for the installation. The constraint of these systems is that $\mathrm{CO}_{2}$ can only be dosed when heat is also required in the greenhouse. The choice of the type of fuel is based on availability, cost per unit and the purity of the gas emissions. Dosing will be specifically controlled according to light levels, temperature and ventilation in greenhouses to ensure the optimum efficiency.

\section{The lighting system}

Light intensity significantly influences other climate parameters in the greenhouse. Artificial illumination is applied in the absence of natural light or when over shaded. For commercial greenhouse production, supplemental lighting is most beneficial in areas that receive less than 4.5 hours average daily sunshine. In many greenhouse growing regions this occurs in winter as a result of the combination of high latitudes and overcast weather. Special lamps are used to provide enough light for normal crops growth during winter and cloudy days. Major lighting system includes LED bulbs, fluorescent lights, tube lamps, metal halide lamps or heat lamps.

\section{Air humidification}

Other than fogger system installations for cooling and humidity control, some systems are generally used for humidification only. Steam boilers are often used in colder regions to supply heat or for humidity control in greenhouses. Heaters are used to create saturated vapour which is pumped into the greenhouse. High pressure humidifier, compressed air is used to split water into tiny droplets and then propel through the greenhouse in an air stream. Pulsators are generally used for irrigation; these are often used for overhead irrigation which also serves for humidification of the greenhouse.

\section{Dehumidification}

Condensation refers to the formation of drops of water from water vapour. Condensation occurs when warm, moist air in a greenhouse comes into contact with a cold surface such as plastic or structural members. The airin contact with the cold surface is cooled to the surface temperature. If the surface temperature is below the dew point temperature of the air, the vapour in the air will condense onto the surface. Condensation is heaviest in greenhouses from sunset to several hours after sunrise. During daylight hours, there is sufficient heating from solar radiation to minimize or prevent condensation, except on very cold, cloudy days. Greenhouses are most likely to experience heavy condensation at sunrise or shortly before. Condensation is a symptom of high humidity and can cause significant problems. Condensation can be a major problem at certain times of the year, impossible to avoid entirely. Anti drop 
covering materials is used for greenhouse dehumidification. "Anti-dripping" films contain special additives which eliminate droplets and form instead a continuous thin layer of water running down the sides.

Table.1 Various green house parameters on micro climate condition

\begin{tabular}{|c|c|c|c|}
\hline Parameters & \multicolumn{3}{|c|}{ Micro climatic parameters } \\
\hline & Temperature & Relative humidity & Solar radiation \\
\hline $\begin{array}{l}\text { Shape of greenhouse } \\
\text { (Quonset \& saw tooth) }\end{array}$ & $\begin{array}{l}3^{0} \mathrm{C} \text { lesser temperature } \\
\text { in sawtooth in } \\
\text { comparison to Quonset } \\
\text { shape }\end{array}$ & $\begin{array}{l}13 \% \text { lesserRH in } \\
\text { Quonset shape in } \\
\text { comparison to saw } \\
\text { tooth shape }\end{array}$ & $\begin{array}{l}5-10 \% \text { greater } \\
\text { radiation in } \\
\text { sawtooth shape. }\end{array}$ \\
\hline Size of greenhouse & $\begin{array}{l}\text { Higher greenhouse } \\
\text { height lesser } \\
\text { temperature at plant } \\
\text { level up to } 2^{0} \mathrm{C} \text {. Greater } \\
\text { length more } 20 \quad \mathrm{~m} \\
\text { without adequate } \\
\text { ventilation increases } \\
\text { temperature. }\end{array}$ & $\begin{array}{c}10-12 \% \text { Higher } \\
\text { humidity at lower } \\
\text { height. }\end{array}$ & $\begin{array}{c}\text { Higher solar } \\
\text { radiation at upper } \\
25 \% \text { height as } \\
\text { compared to lower } \\
\text { levels. }\end{array}$ \\
\hline $\begin{array}{lrr}\text { Cladding } & & \text { material } \\
\text { (Diffused } & \& & \text { UV } \\
\text { Stabilized) } & & \end{array}$ & $\begin{array}{l}\text { UV stabilized clear film } \\
\text { maintained a slightly } \\
\text { higher temperature than } \\
\text { diffused film in both } \\
\text { summer and winter } \\
\text { months. Maximum } \\
\text { temperature reduction } \\
\text { found in diffused film (2 } \\
\left.{ }^{0} \mathrm{C}\right) \text { and UV stabilized (1 } \\
{ }^{0} \mathrm{C} \text { ) in comparison to } \\
\text { outside temperature. }\end{array}$ & $\begin{array}{l}\text { Higher humidity in } \\
\text { UV film cladded } \\
\text { greenhouse. }\end{array}$ & $\begin{array}{l}\text { The percentage of } \\
\text { solar energy } \\
\text { reduction due to } \\
\text { cladding films } \\
\text { duringsummer } \\
\text { was observed as } \\
82 \% \text { and } 76 \% \text { for } \\
\text { the UV and } \\
\text { diffused covers, } \\
\text { respectively. }\end{array}$ \\
\hline Shading and Fogging & $\begin{array}{l}3-4{ }^{0} \mathrm{C} \text { temp reduction } \\
\text { during peak summer } \\
\text { months }\end{array}$ & $\begin{array}{l}15 \text { to } 20 \% \text { increase in } \\
\mathrm{RH}\end{array}$ & No affect found \\
\hline
\end{tabular}

Automatic greenhouse climate control systems

Predicting the microclimate inside a greenhouse can help growers to manage crop production and designers to improve the ventilation and heating systems. The internal microclimate can be investigated by experiment and simulation. As compared with experiments, simulation methods may be performed quicker in less expensive, more flexible and repeatable ways. The influences of natural ventilation and crop transpiration on the indoor microclimate, should be involved in a more realistic way than in most of the existing models, and would make important contributions to the energy and mass balances of a greenhouse.

Early studies of the greenhouse microclimate concentrated on determining the thermal behaviour of the greenhouse (Walker, 1965). 
In order to characterize the mean behaviour of a particular element in the greenhouse, several basic static energy balance models were used (Jolliet, 1991). The usefulness of static models decreases when the time response of the greenhouse becomes comparable with the rates of time change of the boundary conditions. Thus, a number of dynamic climate models have been developed (Zhang et al., 1997).

The dynamic behaviour of the micro climate is a combination of physical processes involving energy transfer (radiation and heat) and mass balance (water vapour fluxes and $\mathrm{CO}_{2}$ concentration).

These processes depend on the outlet environmental conditions, structure of the greenhouse, type and state of the crop and on the effect of the control actuators. Due to the inherent complexity, the development of climate control systems has been mainly based in heuristic rules based on the experience of the growers (Kamp and Timmerman, 1996). During the last few years different control techniques are being applied to solve such problems these are: feed forward control (Rodríguez, 2001), adaptive control (Sigrimis and Rerras, 1996), optimal control (Tap et al, 1996), robust control (Moreno et al., 2002), predictive control (Pinon et al., 2002) etc. There have been several efforts to develop advanced computerized greenhouse climate control systems. Some of the important optimal control approaches proposed (Ioslovich et al., 2009) are: proportional, integral and derivative (PID) controllers, artificial intelligence (AI) such as fuzzy logic systems (FLS), artificial neural networks (ANNs) and genetic algorithms (GAs) to use advanced techniques like predictive, adaptive, robust and non-linear control (Castañeda-Miranda et al., 2008).

\section{Salient research findings}

The study conducted at PFDC IIT Kharagpur to investigate the effect of shape of greenhouses (Quonset and Sawtooth) and cladding films (UV stabilized and diffused films) on micro climate in the greenhouse which can be assessed its suitability for floricultural production (Table 1).

In conclusion the present paper reviewed various greenhouse microclimate parameters and methods to control them to meet the crop requirement. Greenhouse climate control is one of the challenging tasks in precision agriculture. Temperature and humidity are the main variables which have a direct relationship with the plant production. So far researches conducted in different regions are not enough to control and maintain desired temperature, humidity and other parameters which are affordable to plant by economical means applicable to all the agro-climatic regions. However, sophisticated new technologies involving microprocessors, data loggers and automated irrigation and fertigation system allow fully micro-climatic and other input control. There is need for researchers to analyze different control methods and develop affordable greenhouses applicable for different climatic zones.

\section{References}

Al-Helal, A.M., Abdel-Ghany, I.M. 2010. Responses of plastic shading nets to global and diffuse PAR transfer: Optical properties and evaluation. NJAS Wageningen J. Life Sci., 57: 125-132.

ASAE, American Society for Agricultural Engineers. 2000. ANSI/ASAE EP406.3 MAR98, heating, venting and cooling greenhouses, 675: 682.

Bailey, B.J. 2000. Constraints, limitations and achievements in greenhouse natural ventilation. Acta. Hortic., 534: 21-30. 
Bansal, N.K., Minke, G. 1988.C limatic zone and rural housing in India. Scientific Series of International Bureau, Kern. Forschungszentrum, Anlage, Julich, Germany.

Briassoulis, D., Mistriotis, A., Eleftherakis, D. 2007. Mechanical behaviour and properties of agricultural nets - Part I: Testing methods for agricultural nets. Science Direct. Polymer Testing, 26: 822-832.

Contreras-Medina, L.M., Torres-Pacheco, I., Guevara-Gonzal-ez, R.G., RomeroTroncoso R.J., Terol-Villalobos, I.R., De Pascale, S.T., Maggio, A. 2008. Plant stress management in semiarid greenhouses. Acta Hortic., 797: 205215.

Ellis, R.H., Hadley, P., Roberts, E.H., Summerfield, R.J. 1980. Quantitative relations between temperature and crop development and growth. Climatic change and plant genetic Resources, Belhaven Press. Landon: 85-115.

Ioslovich, I., Gutman, P., Linker, R. 2009. Hamilton-Jacobi-Bellman formalism for optimal climate control of green-house crop. Automatica, 45(5): 1227-1231.

Jackson, R.D., Idso, S.B., Reginato, R.J., Pinter, P.J. 1981. Canopy temperature as crop water stress indicator. Water Res. Res., 17: 1133-1138.

Joliet, O. 1991. An improved static model for predicting the energy consumption of a greenhouse, Agricultural and Forest Meteorol., 55: 265-294.

Kamp, P.G.H., Timmerman, G.J. 1996. Computerized environmental control in greenhouses. Ed. IPC Plant, The Netherlands.

Katsoulas, N. Kittas, C. Tsirogiannis, H., Kitta E, Savvas, D. 2007. Greenhouse microclimate and soilless pepper crop production and quality as affected fog evaporative cooling system. Transaction of ASABE, 50: 1831-1840.
Kittas, C., Boulard, T., Mermier, M., Papadakis, G. 1996. Wind induced air exchange rates in a greenhouse tunnel with continuous side openings. J. Agric. Eng. Res., 65: 37-49.

Kittas, C., Karamanis, M. \&Katsoulas, N. 2005. Air temperature regime in a forced ventilated greenhouse with rose crop. Energy \& Buildings, 37(8): 807812.

Lorenzo, P., Maroto, C. and Castilla, N. $1990 . \mathrm{CO}_{2}$ in plastic greenhouse in Almería (Spain). Acta Hort., 268: 165169.

Moreno, J.C., Berenguel, M. Rodríguez, F., Baños, A. 2002.Robust control of greenhouse climate exploiting measurable disturbances. $15^{\text {th }}$ IFAC world congress, Barcelona.

Nisen, A., Sirjacobs, M., von Zabeltitz, C. 1984. Protected cultivation in Mediterranean climate, greenhouses in Egypt. FAO, Rome.

Nomura, E. S., Lima, J. D., Rodrigues, D. S., Garcia, V. A. 2009. Crescimento e produção de antúriocultivado sob diferentesmalhas de sombreamento. Ciência Rural, 39:1394-1400.

Oren-Shamir, M., Gussakovsky, E.E., Shpiegel, E., Nissim-Levi, A., Ratner, K., Ovadia, R., Giller, Yu, E., Shahak, Y. 2001. Coloured shade nets can improve the yield and quality of green decorative branches of Pittosphorum variegatum. J. Horticultural Sci. Biotechnol., 76: 353-361.

Ould Khaoua, S.A., Bournet, P.E., Migeon, C., Boulard, T., Chasseriaux, G. 2006.Analysis of green-house ventilation efficiency based on computational fluid dynamics (CFD). Biosystems Eng., 95(1): 83-88.

Pearson, S., Hadley, P. and Wheldon, A.E. 1995.A model of the effect of day and night temperature on the height of chrysanthemum. ActaHorticulturae, 
378: 71-80.

Piñón, S.M. Camacho, E.F., Kuchen, B. 2002. Constrained predictive control of a greenhouse. $15^{\text {th }}$ IFAC World Congress, Barcelona; Spain.

Robledo, F.P., Martin, L.V. 1981. Aplicatión de los plásticosem la agricultura. Madrid: Mundi-Prensa. 552p.

Rodríguez, F., Berenguel, M., Arahal, M.R. 2001.Feedforward controllers for greenhouse climate control based on physical models". ECC01, Porto, Portugal.

Sanchez-Guerrero, M.C., Lorenzo, P., Medrano, E., Castilla, N., Soriano, T. and Baille, A. 2005.Effect of variable CO2enrichment on greenhouse production in mild winter climates. Agric. Forest Meteorol., 132: 244-252.

Shahak, Y., Lahav, T., Spiegel, E., PhilosophHadas, S. 2002. Growing aralia and monstera under colored shade nets.
Olam Poreah, 13: 60-62.

Sigrimis, N., Rerras, N. 1996. A linear model for greenhouse control, Trans. ASAE., 39(1): 253-261.

Tap, F., van Willigenburg, L.G., van Straten, G. 1996. Receding horizon optimal control of greenhouse climate based on the lazy man weather prediction, $13^{\text {th }}$ IFAC World Congress; San Francisco; USA; pp. 387-392.

Tiwari, G.N. 2003. Greenhouse technology for controlled environment in India. Narosa Publishing House.

Walker, J.N. 1965. Predicting temperatures in ventilated greenhouses. Transactions of the ASAE, 8(3): 445-448.

Zhang, S., Mahrer, Y. Margolin, M. 1997. Predicting the microclimate inside a greenhouse: an application of a onedimensional numerical model in an unheated greenhouse, Agri. Forest Meteorol., 86: 291-297.

\section{How to cite this article:}

Santosh, D.T., K.N. Tiwari, Vikas Kumar Singh and Raja Gopala Reddy, A. 2017. Micro Climate Control in Greenhouse. Int.J.Curr.Microbiol.App.Sci. 6(3): 1730-1742.

doi: https://doi.org/10.20546/ijcmas.2017.603.199 